\title{
Gions

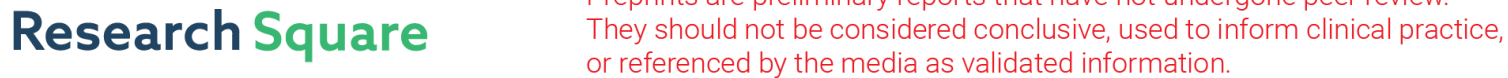 \\ COVID-19 Re-infection or Relapse? A Retrospective Multi Center Cohort Study From Iran
}

\section{Mohamadreza Salehi}

Tehran University of Medical Sciences

SeyedAhmad SeyedAlinaghi

Tehran University of Medical Sciences

llad Alavi Darazam

Shahid Beheshti University of Medical Sciences School of Medicine

\section{Payam Tabarsi}

Shahid Beheshti University of Medical Sciences School of Medicine

\section{Mohammad Mahdi Rabiei}

Shahid Beheshti University of Medical Sciences School of Medicine

Firouze Hatami

Shahid Beheshti University of Medical Sciences School of Medicine

\section{Somayeh Ghadimi}

Shahid Beheshti University of Medical Sciences School of Medicine Hamid Emadi Koochak

Tehran University of Medical Sciences

\section{Parastoo Veisi}

Shahid Beheshti University of Medical Sciences School of Medicine

\section{Fereshte Ghiasvand}

Tehran University of Medical Sciences

\section{Ali Asadollahi-Amin ( $\nabla$ amiyaneh@gmail.com )}

Tehran University of Medical Sciences School of Medicine https://orcid.org/0000-0001-5260-6387

\section{Research}

Keywords: COVID-19, Reactivation, Re-infection, Relapse

Posted Date: March 1st, 2021

DOI: https://doi.org/10.21203/rs.3.rs-262191/v1

License: (1) This work is licensed under a Creative Commons Attribution 4.0 International License. Read Full License 


\section{Abstract}

\section{Background}

More than one year of emerging COVID 19 infection, no signs of the pandemic remission appear. Returning of symptomatic patients who had a history of recovered COVID-19 disease with a new positive SARS Cov-2 PCR test after several weeks to months of a negative PCR result is one of the novels challenging phenomena during the pandemic. In this study, we determined the clinical and laboratory characteristics of these Iranian patients and discussed possible reasons.

\section{METHOD}

We retrospectively investigated the SARS Cov-2 PCR tests performed in the three referral hospitals six months after the pandemic onset. All patients who had the following criteria were included in the study: two SARS COV2 PCR positive tests three months apart, have no symptoms, and a negative PCR between the two positive tests, access to the patient and his medical information. Then, retrospectively recorded the clinical and laboratory characteristics of the eligible patients. We also compare clinical and laboratory features of the second episode to the first.

\section{RESULT}

A total of 32,567 tests were performed, of which 1899 patients. Finally, 37 cases were eligible in the study based on our criteria. The majority of patients were male and nurses. The mean body mass index was $25.84 \pm 3.25$. The mean age was $37.54 \pm 15.16$ years old. Weakness, myalgia, and fever were the most clinical presentation symptoms in both episodes. Chest Computed Tomography (CT) scan showed pneumonia in $56.8 \%$ and $43.2 \%$ of cases in the first and second episodes, respectively. The mean duration between the discharge and second presentation was $117 \pm 61.42$ days. Seven (18.9\%) patients hospitalized in the second episode compared to $2(5.4 \%)$ cases in the first. The clinical, radiological, and laboratory characteristics were not significantly different between the two episodes except for significantly more dexamethasone usage in the second one $(p=0.03)$.

\section{CONCLSION}

Although we could not perform the phylogenic sequencing of SARS-CoV-2 and viral culture in the representing symptomatic patients with positive RT-PCR, prolonged duration between two episodes suggest probably reinfection in our cases. Finally, this clinical phenomenon may be more common in healthcare providers without a significant consequence.

\section{Introduction}

More than one year of emerging severe acute respiratory syndrome coronavirus 2 (SARS-CoV-2), cause of COVID 19 disease, is still going on with over 80 million people confirmed cases and about two million Deaths [1], no signs of the pandemic remission appear. Lacking curative treatment and vaccines, along 
with new manifestations, make challenges in the management of the disease. Positive real-time reverse transcriptase-polymerase chain reaction (RT-PCR) test results in patients recovered from the clinical symptoms with documented negative RT-PCR several days to months later is one of these unknown novel phenomena during the pandemic.

We determined clinical as well as laboratory characteristics of Iranian COVID 19 patients who returned with symptoms compatible with COVID-19 and positive RT-PCR for SARS-CoV-2 after recovery from the first episode. Moreover, we review the literature and discussed possible explanations.

\section{Material And Methods}

We retrospectively evaluated the results of SARS Cov-2 PCR tests in the laboratories registries of the three main hospitals (Imam Khomeini Hospital Complex, Masih Daneshvari Hospital and Imam Hussein Hospital Medical Center) in Tehran during the first 6 months of the pandemic. All patients who had the following criteria were included in the study: Two positive tests three months apart, there should be a negative PCR between the two positive tests, access to the patient and his medical information in both episodes. Then, we interviewed with all eligible patients, and recorded patients' clinical, laboratory as well as radiological characteristics in data collection forms. We also compare clinical and laboratory characteristics of the second episode to the first.

Two reviewers evaluated the data separately. The mild, moderate, and severe diseases were defined according to WHO guidelines [2]. Nasopharynx swab sample collection, detection of SARS-CoV-2 and COVID-19 pneumonia definition were performed based on the national recommendations.

This study was approved by the ethical committee of Amir Alam Hospital, Tehran University of Medical Sciences with the ethics code number of IR.TUMS.VCR.REC.1399.088. Informed consent was obtained from all participants.

Statistical analysis was performed using SPSS, version 22.0. Quantitative and qualitative data we reported as mean $\pm S D$ and number (\%) respectively. Continuous variables and categorical variables were compared using the independent $t$-test and the $\chi 2$-test respectively. $P$ value less than 0.05 was considered statistically significant.

\section{Results}

A total of 32,567 tests were performed, of which 1899 patients were tested three times and between them 138 patients had two positive tests. Finally, 37 cases could be included in the study based on our criteria. Clinical and laboratory characteristics of thirty-seven COVID-19 patients in the first and second episodes are shown in Table 1. Among thirty-seven patients, twenty-four persons (64.9\%) were male. The mean age was $37.54 \pm 15.16$ years (range from 24 to 94 -year-old). Majority were nurse (37.8\%) and other healthcare workers (HCW) (35.1\%). Seven patients (18.9\%) had cardiovascular diseases. The mean body mass index (BMI) was $25.84 \pm 3.25$. CT scan showed pneumonia in $56.8 \%$ of cases in the first episode. 
Weakness (75.7\%), myalgia (73.0\%) and fever (64.9\%) were the most clinical presentation symptoms in the first visit. At first exposure, the mean saturation $\mathrm{O}_{2}\left(\mathrm{SO}_{2}\right)$ was $92.9 \pm 4.07$, only $2(5.4 \%)$ patients had severe disease, two (5.4\%) cases hospitalized and no one died. In addition, lymphopenia was observed in 4 (33.3\%) of cases. Considering treatment, $13(35.1 \%)$ patients received antiviral therapy and dexamethasone only for one (2.7\%) person administered in the first episode. 
Table 1

Clinical, and laboratory findings of patients with COVID-19 in the two episodes, Tehran, Iran, 2020-2021

\begin{tabular}{|c|c|c|c|}
\hline \multirow[t]{2}{*}{ Variables } & First & Second & \multirow[t]{2}{*}{ P-value } \\
\hline & Episode & Episode & \\
\hline \multicolumn{4}{|l|}{ Dyspnea } \\
\hline Yes & $12(32.4 \%)$ & $14(37.8 \%)$ & \multirow[t]{2}{*}{0.63} \\
\hline No & $25(67.7 \%)$ & $23(62.2 \%)$ & \\
\hline \multicolumn{4}{|l|}{ Fever } \\
\hline Yes & 24 (64.9\%) & $27(73.0 \%)$ & \multirow[t]{2}{*}{0.45} \\
\hline No & 13 (35.1\%) & $10(27.0 \%)$ & \\
\hline \multicolumn{4}{|l|}{ Chills } \\
\hline Yes & 22 (59.5\%) & $24(66.7 \%)$ & \multirow[t]{2}{*}{0.52} \\
\hline No & 15 (40.5\%) & 12 (33.3\%) & \\
\hline \multicolumn{4}{|l|}{ Myalgia } \\
\hline Yes & 27 (75\%) & 31 (83.8\%) & \multirow[t]{2}{*}{0.35} \\
\hline No & 9 (25\%) & $6(16.2 \%)$ & \\
\hline \multicolumn{4}{|l|}{ Cough } \\
\hline Yes & 18 (48.6\%) & $21(56.8 \%)$ & \multirow[t]{2}{*}{0.49} \\
\hline No & $19(51.4 \%)$ & $16(43.2 \%)$ & \\
\hline \multicolumn{4}{|l|}{ Nausea } \\
\hline Yes & $9(25 \%)$ & $10(27 \%)$ & \multirow[t]{2}{*}{0.84} \\
\hline No & 27 (75\%) & $27(73 \%)$ & \\
\hline \multicolumn{4}{|l|}{ Diarrhea } \\
\hline Yes & $9(25 \%)$ & $9(24.3 \%)$ & \multirow[t]{2}{*}{0.95} \\
\hline No & 27 (75\%) & $28(75.7 \%)$ & \\
\hline \multicolumn{4}{|l|}{ weakness } \\
\hline Yes & $28(75.7 \%)$ & 31 (83.8\%) & \multirow[t]{2}{*}{0.39} \\
\hline No & $9(24.3 \%)$ & $6(16.2 \%)$ & \\
\hline
\end{tabular}




\begin{tabular}{|c|c|c|c|}
\hline \multirow[t]{2}{*}{ Variables } & First & Second & \multirow[t]{2}{*}{ P-value } \\
\hline & Episode & Episode & \\
\hline \multicolumn{4}{|l|}{ Antiviral therapy } \\
\hline Yes & $13(35.1 \%)$ & $13(35.1 \%)$ & $>0.9$ \\
\hline No & $24(64.9 \%)$ & $24(64.9 \%)$ & \\
\hline \multicolumn{4}{|l|}{ Taking Steroid } \\
\hline Yes & $1(2.7 \%)$ & $8(21.6 \%)$ & 0.03 \\
\hline No & $36(97.3 \%)$ & $29(78.4 \%)$ & \\
\hline \multicolumn{4}{|l|}{ Outcome } \\
\hline Death & $0(0 \%)$ & $1(3.1 \%)$ & $>0.9$ \\
\hline Discharge & $32(100 \%)$ & $31(96.9 \%)$ & \\
\hline \multicolumn{4}{|l|}{ Disease Level } \\
\hline Mild & $24(64.9 \%)$ & $19(51.4 \%)$ & 0.12 \\
\hline Moderate & $11(29.7 \%)$ & $10(27 \%)$ & \\
\hline severe & $2(5.4 \%)$ & $8(21.6 \%)$ & \\
\hline \multicolumn{4}{|l|}{ Hospitalization } \\
\hline Yes & $2(5.4 \%)$ & $7(18.9 \%)$ & 0.15 \\
\hline No & $35(94.6 \%)$ & $30(81.1 \%)$ & \\
\hline \multirow[t]{2}{*}{02 Saturation } & Mean (SD) & Mean (SD) & 0.13 \\
\hline & $92.9(4.1)$ & $90.1(7.3)$ & \\
\hline \multirow[t]{2}{*}{ C-reactive protein (CRP) (mg/liter) } & Mean (SD) & Mean (SD) & 0.73 \\
\hline & $23.6(32.7)$ & $28.1(30.3)$ & \\
\hline \multirow[t]{2}{*}{ White Blood Cell (WBC) (cell/mcL) } & Mean (SD) & Mean (SD) & 0.55 \\
\hline & $7049.2(1889.2)$ & 7595 (2862.5) & \\
\hline \multirow[t]{2}{*}{ Lymphocyte count (cell/mcL) } & Mean (SD) & Mean (SD) & 0.05 \\
\hline & $1401.4(793.3)$ & $2093.9(977.5)$ & \\
\hline \multicolumn{4}{|l|}{ Chest CT scan } \\
\hline Positive & $21(56.8 \%)$ & $16(43.2 \%)$ & 0.25 \\
\hline Negative & $16(43.2 \%)$ & $21(56.8 \%)$ & \\
\hline
\end{tabular}


Comparing two episodes, there were no significant differences between clinical and laboratory characteristics of thirty-seven COVID-19 patients, except for dexamethasone use $(p=0.03)$ (Table 1$)$. The mean duration between two episodes was $117 \pm 61.42$ days.

On the second exposure, CT scan showed pneumonia in $43.2 \%$ of cases, Weakness (83.8\%), myalgia $(83.8 \%)$ and fever $(73 \%)$ were the most clinical presentation symptoms, the mean $\mathrm{SO}_{2}$ was $90.1 \pm 7.3,8$ $(21.6 \%)$ patients had severe disease, seven $(18.9 \%)$ cases hospitalized and one $(2.7 \%)$ person died. lymphopenia was observed in $2(12.5 \%)$ of cases. Considering treatment in this episode, $13(35.1 \%)$ patients received antiviral therapy and dexamethasone for eight (21.6\%) persons administered (Table 1).

\section{Discussion}

In this study, the majority of cases were male, and the most predisposing factor was cardiovascular diseases. Weakness, myalgia, and fever were the most clinical presentation symptoms in each episode. Pneumonia was detected in nearly half of the patients in both episodes.

Except for significantly more dexamethasone consumption in the second episode; the clinical and laboratory characteristics were not significantly different between the two ones. Growing evidence in favor of dexamethasone usage could explain this finding. Severe disease was only observed in less than one-third of all episodes.

Ye et al. reported similar clinical characteristics in the patients with a second episode of COVID-19. Fatigue, fever, and cough were the most reported symptoms respectively, and none of them had dyspnea or severe pneumonia. In contrast, all elderly re-admitted COVID-19 patients, reported by Lafaie et al. died. They also remained asymptomatic between two episodes [3, 4]. Li et al. reported chest pain and cough as re-presenting symptoms, whereas fever and hypoxia reported in another patient who re-admitted because of COVID 19. Both of them survived although the latter referred to an inpatient rehabilitation facility $[5,6]$. At least four case series reported lymphopenia and elevated concentrations of CRP in most re-admitted patients in $[3,4,7,8]$. However, in line with our series, Wang and Li reported normal lymphocyte count and CRP level in majority of re-admitted patients $[9,10]$.

Among potential host risk factors for the second episode (gender, older age, and taking immunosuppressive agents) mentioned by Ye et al., our patients was mainly male and had cardiovascular diseases. Since six of $16(38 \%)$ patients reported in the previous series $[3,7]$ and all older patients noted by Lafaie received corticosteroids in the first episode, older age and interleukins suppression mediated by steroids may play a significant role [3, 4]. However, our patients were relatively younger.

The mean 117 days between two episodes in our study is apparently longer than 4 to 17 days reported in previous studies $[11,10]$. However, Lafaie et al., reported this period more than 30 days for a dead old patient [4]. 
Considering chest CT features of re-admitted patients, in contrast to our series, Li et al. showed a changing pattern from reticulation to Ground-glass opacity (GGO) indicating active infection, which occurred in $40 \%$ of patients [10]. However, most re-hospitalized patients in the Zheng series had improved CT abnormalities [12].

Several scenarios have been proposed to explain this phenomenon included persistent infection, reinfection, relapse or reactivation, and inflammatory rebound.

\section{Persistent infection}

The prolonged clinical course of COVID-19 disease for more than 2 months has been documented [13]. In addition, continuous viral shedding irrespective of clinical symptoms reported as long as 83 days by Li et al. [14]. The average range of viral shedding marked by positive RT-PCR was noted 20 to 22 days after symptoms onset [6]. On the other hand, the false-negative rate of RT-PCR results was $12.5 \%$ in one study [15]. It could be due to low viral loads, collecting specimens by different methods, and laboratory errors [10]. Therefore, prolonged viral clearance or persistent infection rather "turning positive again" or "reoccurring" have been proposed [16]. Moreover, Wang et al., supported transmission of the whole or traces of the virus from the lower respiratory tract to the throat or nose as their patients had only slight coughs [9]. However, our patients as well as Ye, Lafaie, and Gousseff series remained asymptomatic between two episodes and presented again with notable symptoms such as fever and hypoxia, making this scenario in doubt $[3,4,7]$. Besides, re-emergence of GGOs in at least $40 \%$ re-admitted patients in Li et al. series provides another clue versus persistent infection [10]. Finally, culture the virus in the second episode and showing the cytopathic effect of SARS-CoV-2 as Gousseff et al. done for two patients [7], demonstrated the true; however, we could not perform it. Moreover, the RT-PCR cycle threshold (Ct) value below 24 may correlate to viable SARS-CoV-2, which was not available in our RT-PCR results [17].

\section{Reinfection}

As a rule, circulating antibodies, memory B cells, and memory $T$ cells are three essential parts of the immune system to prevent viral reinfection. The presence of SARS-CoV-2-specific T cells documented in COVID-19, could quarantine the immunity of recovered patients even in the absence of specific antibodies; however, potential anamnestic $B$ cell and $T$ cell responses remains obscure [18].

Since no recurrent disease was observed after re-challenging the monkeys with the same strain of SARSCoV-2, Duggan et al., concluded that different strains could responsible for reinfection [6]. Unfortunately, we could not perform the phylogenic sequencing in the returning patients to evaluate this conclusion.

Since four HCW of the Gousseff series had mild symptoms in both episodes along with persistent exposure could be expected, they suggested reinfection might occur [7]. In contrast, in view of the Ravioli et al., series, reinfection was less likely given the fact that the prevalence of COVID-19 was low in that region [8]. Most recently, To et al. documented reinfection in an immunocompetent patient by 
phylogenetic analysis of the virus in the two episodes, challenging herd immunity or even vaccination [19].

\section{Relapse or reactivation}

While a shorter duration between two episodes was in favor of reactivation [4], the mean time in our cases was more than 110 days. Suboptimal control of the SARS-CoV-2 infection or presence of sanctuaries was purposed as causes of relapse in these patients [7]. Host underlying conditions, SARSCoV-2 viral load, and immunosuppression state in the first episode might predispose the patient to reactivation [3]. It seems old patients in Lafaie et al., series had a reactivation episode given the reexposure was less likely and relatively short duration between two episodes; also, two patients had negative serology at re-admission [4]. Seven older patients with comorbidities with a median of 11 symptom-free days reported by Gousseff et al., appear to have a similar scenario [7].

In line with the Gousseff series, our patients had mainly mild disease and were healthcare personnel. In addition, the prevalence of COVID-19 was high in the period of study and the mean duration between two episodes was nearly four months. Therefore, reinfection is probably the best scenario to justify our case series.

\section{An inflammatory rebound}

Dysregulated immune reaction might be responsible for clinical deterioration, but the virus cultured successfully in re-admitted patients of pervious series making this hypothesis less likely [7]. All of our patients also had positive RT-PCR for SARS-CoV-2 in the second episode.

Another diagnosis:

Recurrence of clinical symptoms could be due to other bacteria and viruses causing pneumonia, or secondary complications such as pulmonary embolism; however, nearly all differential diagnosis of the COVID 19 infection in our and Lafaie et al., series had been ruled out [4].

\section{Conclusion}

Although we could not cultivate the virus and perform the phylogenic sequencing of SARS-CoV-2 in the representing patients with positive RT-PCR for SARS-CoV-2 and symptoms compatible with COVID-19, but prolonged duration between two episodes suggests probably reinfection in our cases. Given the substantial impact on public health and the outcome of vaccination, investigation of the precise physiopathology of this phenomenon is urgently warranted. Finally, this clinical phenomenon may be more common in healthcare providers without a significant consequence.

\section{Declarations}

Ethics approval and consent to participate 
We also declare that the study was performed according to the international, national, and institutional rules considering animal experiments, clinical studies, and biodiversity rights.

\section{Consent for publication}

All authors of this manuscript have read and approved the final version submitted. This article has not been published and is not under consideration for publication elsewhere.

\section{Availability of data and materials}

All information provided in this article can be obtained from the author on request.

\section{Competing interests}

There is no conflict of interest regarding the publication of this manuscript.

\section{Funding}

All affiliations with, or financial involvement in any entity with a financial interest in, or in competition with, the manuscript's subject matter is disclosed. This includes stock ownership, employment, consultancies, honoraria, grants, patents, and royalties. This research did not receive any specific grant from funding agencies in the public, commercial, or not-for-profit sectors.

\section{Authors' contributions}

Mohamadreza Salehi, llad Alavi Darazam, Payam Tabarsi collected the data and wrote the initial manuscript.

Mohammad Mahdi Rabiei, Firouze Hatami, Somayeh Ghadimi, Hamid Emadi Koochak, and Parastoo Veisi, analyzed the date and revised the manuscript.

SeyedAhmad SeyedAlinaghi, Fereshte Ghiasvand and Ali Asadollahi-Amin wrote and revised the final manuscript and submitted the manuscript.

\section{Conflict of Interest}

The authors have no conflict of interest.

\section{Acknowledgements}

The authors thank the staff in the hospital for their help.

\section{References}


1. World Health Organization. Coronavirus Disease (COVID-2019) Situation Reports [updated 2020 December 24; cited 2020 December 24]. Available from URL: https://www.who.int/emergencies/diseases/novel-coronavirus-2019/situation-reports

2. World Health Organization. Coronavirus Disease (COVID-2019) Clinical management of COVID-19 Interim guidance [updated 2020 May 27; cited 2021 January 13]. Available from URL: https://apps.who.int/iris/bitstream/handle/10665/332196/WHO-2019-nCoV-clinical-2020.5eng.pdf

3. Ye G, Pan Z, Pan Y, Deng Q, Chen L, Li J, Li Y, Wang X. Clinical characteristics of severe acute respiratory syndrome coronavirus 2 reactivation. Journal of Infection. 2020 May 1; 80(5):e14-7.

4. Lafaie L, Célarier T, Goethals L, Pozzetto B, Grange S, Ojardias E, Annweiler C, Botelho-Nevers E. Recurrence or Relapse of COVID-19 in Older Patients: A Description of Three Cases. Journal of the American Geriatrics Society. 2020 Aug.

5. Li XJ, Zhang ZW, Zong ZY. A case of a readmitted patient who recovered from COVID-19 in Chengdu, China. Critical Care. 2020 Dec; 24:1-3.

6. Duggan NM, Ludy SM, Shannon BC, Reisner AT, Wilcox SR. A case report of possible novel coronavirus 2019 reinfection. The American journal of emergency medicine. 2020 Jan 1.

7. Gousseff M, Penot P, Gallay L, Batisse D, Benech N, Bouiller K, Collarino R, Conrad A, Slama D, Joseph C, Lemaignen A. Clinical recurrences of COVID-19 symptoms after recovery: viral relapse, reinfection or inflammatory rebound?. Journal of Infection. 2020 Jun 30.

8. Ravioli S, Ochsner H, Lindner G. Reactivation of COVID-19 pneumonia: A report of two cases. The Journal of Infection. 2020 May 7.

9. Wang M, Hu Z, Liu J, Pang P, Fu G, Qian A, Chen S, Lin L, Cao G, Sun H, Yang Y. Positive RT-PCR Test Results in Discharged COVID-19 Patients: Reinfection or Residual?.

10. Li C, Luo F, Xie L, Gao Y, Zhang N, Wu B. Chest CT study of fifteen COVID-19 patients with positive RTPCR retest results after discharge. Quantitative imaging in medicine and surgery. 2020 Jun; 10(6):1318.

11. Hoang VT, Dao TL, Gautret P. Recurrence of positive SARS-CoV-2 in patients recovered from COVIDJournal of Medical Virology. 2020 May 25.

12. Zheng J, Chen F, Han S, Zhou R, Li F, Liu H, Lu J, Wu X. Recovery of pneumonia in 27 discharged COVID-19 patients with positive virus detection. Quantitative Imaging in Medicine and Surgery. 2020 Jul; 10(7):1572.

13. Yang JR, Deng DT, Wu N, Yang B, Li H, Pan X. Persistent viral RNA positivity during recovery period of a patient with SARS-CoV-2 infection. J Med Virol. 2020:jmv.25940.

14. Li N, Wang X, Lv T. Prolonged SARS-CoV-2 RNA shedding: not a rare phenomenon. J Med Virol. 2020

15. Li Y, Lin Y, Li J, et al. Stability issues of RT-PCR testing of SARS-CoV-2 for hospitalized patients clinically diagnosed with COVID- J Med Virol. 2020. 
16. Xiao AT, Tong X, Zhang S. False-negative of RT-PCR and prolonged nucleic acid conversion in COVID19: Rather than recurrence. J Med Virol 2020.

17. Bullard J, Dust K, Funk D, Strong JE, Alexander D, Garnett L, Boodman C, Bello A, Hedley A, Schiffman Z, Doan K. Predicting infectious SARS-CoV-2 from diagnostic samples. Clinical Infectious Diseases. 2020 May 22.

18. Liu A et al., Disappearance of antibodies to SARS-CoV-2 in a -COVID-19 patient after recovery, Clinical Microbiology and Infection

19. To KK, Hung IF, Ip JD, Chu AW, Chan WM, Tam AR, Fong CH, Yuan S, Tsoi HW, Ng AC, Lee LL. COVID19 re-infection by a phylogenetically distinct SARS-coronavirus-2 strain confirmed by whole genome sequencing. Clinical Infectious Diseases. 2020 Aug 25.

\section{Supplementary Files}

This is a list of supplementary files associated with this preprint. Click to download.

- GraphicalAbstract.jpg 